\title{
TELESPEECH THERAPY PILOT PROJECT: STAKEHOLDER SATISFACTION
}

\author{
SENA CRUTCHLEY, MA \& MiCHAEL CAMPBEll, MA, MBA \\ THE UNIVERSITY OF NORTH CAROLINA AT GREENSBORO
}

\section{ABSTRACT}

This pilot study of a school-based telepractice pilot project in a rural, remote county of North Carolina investigated the satisfaction of parents/caregivers, teachers, and administrators with a year-long telespeech therapy program delivered by a university clinic. Upon completion of the almost year-long project, a satisfaction survey incorporating a 5-point equal-appearing Likert scale ( $1=$ strongly disagree; $5=$ strongly agree) was disseminated to the stakeholders. The results were sorted by the three populations surveyed and indicated stakeholder satisfaction with student progress toward their speech and language goals, and clinician accessibility and responsiveness (mean ratings $>4$ points). The respondents $(\mathrm{N}=23)$ also indicated they would "recommend TeleSpeech Therapy to other school districts" (mean rating: 4.3). The only mean rating below 4.0 was associated with teacher responses to the statement: "My expectations for the TeleSpeech Therapy program have been met" (mean rating: 3.92). Overall, parents/caregivers, teachers, and administrators appeared to find telepractice a satisfactory service delivery model for school-based speech-language therapy.

\section{SATISFACTION WITH TELESPEECH THERAPY PILOT PROJECT}

\section{TELESPEECH PROJECT GENESIS}

According to the Council for Allied Health in North Carolina (2001), there is a disparity between the number of speech-language pathologists (SLPs) working in rural and remote areas and those in urban areas, with the supply of SLPs "...substantially below the national ratios in nonmetropolitan and traditionally underserved health professional shortage areas" (p. 29). With that disparity, children and adults in rural areas may not have access to speech-language therapy services (Mashima \& Doarn, 2008).

The American Speech-Language-Hearing Association (ASHA) (2002; 2005) states that one way to improve access to speech-language pathology services for underserved populations is through telepractice. Telepractice involves delivering speech-language pathology services at a distance through the use of telecommunications technology. Anecdotal evidence and empirical research to date suggest that services provided by telepractice are effective (Brennan, Georgeadis, Baron, \& Barker, 2004; Forducey, 2006; Kully, 2000; Mashima et al., 2003; Mashima \& Doarn, 2008).

In the spring of 2007, the Speech and Hearing Program (SHP) of The University of North Carolina at Greensboro (UNCG) began investigating where the greatest needs for speech-language pathology services existed in North Carolina. The most significant needs were found to be in the rural mountainous areas of the west and the rural areas at the coast. The director of the SHP contacted the directors of Exceptional Children (EC) of the school districts in those areas. He presented the concept of telepractice and proposed that the SHP could provide those services to their students via the SHP TeleSpeech Therapy program.

One EC Director expressed strong interest in the program. Her school district, in a rural and remote county of North Carolina, had been short staffed by at least one speech-language pathologist (SLP) for about three years despite significant recruitment efforts. Due to that shortage, the students at one elementary school had been without or received a minimal amount of speech therapy services for over a year. In the summer of 2007, the EC Director invited representatives of the SHP to visit with her and her colleagues to discuss telepractice. Thus, the Director and an SLP of the UNCG Speech and Hearing Program met with the EC Director, assistant school superintendent, information technology staff, and a local SLP to talk about the proposed program. Program specifics and needs related to technology, staffing, caseload, documentation, TeleSpeech room location and setup, and scheduling were discussed. The EC director and assistant superintendent then disseminated that information to the local school board. 
Upon approval by the local school board, the UNCG Speech and Hearing Program entered into a contractual arrangement with that school district to provide speechlanguage pathology services to one elementary school. Because there was only one TeleSpeech SLP and forty students represented a manageable caseload, about half of the eighty students designated to receive speechlanguage therapy services at that school were invited to participate in the TeleSpeech Program. Of the eighty students, the UNCG Speech and Hearing Program selected the speech impaired students who stuttered, who experienced difficulty with speech sound production, and who had more severe language impairments. Until another SLP was identified by the school district to serve the remaining students, mainly those with milder language impairments, the TeleSpeech SLP provided teachers and parents of those students with materials and activities that they could use in the regular classroom and at home.

The SLP who would be providing the TeleSpeech Therapy services sent written notification about the program, including benefits and limitations of telepractice, to the parents/guardians of those students selected to receive TeleSpeech services. The letter explained that telespeech therapy is provided through live, interactive videoconferencing. The website of a similar telepractice program in Texas was provided because it contained videos of telespeech sessions. The telepractice SLP also provided her telephone and email contact information and encouraged the parents/guardians to contact her with any questions or comments. In addition, she invited the parents/guardians to observe therapy sessions.

Teachers were informed about the telepractice project by the local administrators. In addition, the telepractice SLP contacted the teachers by email to tell them about the program and encourage collaboration.

The telepractice equipment was installed in the TeleSpeech Room of the elementary school by the district's information technology (IT) staff. Any needed technical support specific to videoconferencing was provided to the IT staff by the equipment's vendor. Only the SLP, IT staff, and paraprofessional assigned to be physically present with the students during speech therapy needed to be trained and skilled in using the equipment. Because the TeleSpeech Therapy program did not involve data sharing in which computer access is available to both sites, the students, parents, teachers, and administrators did not directly handle the equipment. The SLP at the hub site transmitted audiovisual data and content (e.g., images from the computer or document camera) to the remote school site. The paraprofessional at the remote site turned the system on and off and, under the direction of the SLP, used the remote control to zoom the camera image in and out, move the camera, and select the image that would be displayed full-screen. Thus, technical training was not needed for the students, parents, teachers, or administrators.
Despite the readiness of the school district and the UNCG Speech and Hearing Program, implementation of the TeleSpeech Therapy pilot project was delayed for several months. Until the project began, the SLPs from the UNCG Speech and Hearing Program provided therapy services in person. Parents/guardians were notified in writing about the delay. In March, 2008, the Speech and Hearing Program began the pilot project, with the permission of the North Carolina Board of Examiners for Speech-Language Pathologists and Audiologists. Through this project, speech-language therapy was provided to preschool and elementary school children through February 24, 2009. The children received therapy services addressing speech sound production, language, and stuttering, according to what was outlined in their Individualized Education Programs (IEPs). The frequency and duration of therapy sessions varied depending on the needs of the child. The paraprofessional employed by the public school system escorted the students to and from the speech room and was present in the room with the children during every speech therapy session. She also served as the conduit between the SLP and the teachers and parents/guardians when it was not feasible for those parties to speak directly.

Contact was maintained between the SLP, teachers, and parents/guardians throughout the project. The SLP and parents/guardians interacted at IEP annual review meetings, which occurred at least once per year. Additionally, parents/guardians were updated about their children's progress through regular progress reports. The majority of parents/guardians did not observe telepractice sessions. Regarding the teachers, they interacted with the SLP at their students' IEP meetings, and they communicated throughout the year by telephone and email to discuss goals, progress, and treatment activities. Several administrators observed telepractice therapy sessions and participated in IEP meetings through videoconferencing.

Engaging in the TeleSpeech Therapy pilot project required a significant commitment by the school district, parents, and the UNCG Speech and Hearing Program. If TeleSpeech Therapy was to continue beyond that first year, the SHP would have to demonstrate that it was successful. One measure of the success of telepractice is the satisfaction of the stakeholders involved. Hill et al. (2006) indicated that client and clinician satisfaction with the telepractice service delivery model is critical to successful telepractice programs. To date, surveys of patient/client satisfaction have indicated high levels of satisfaction with speech therapy provided by telepractice (ASHA, 2005, Brennan et al., 2004, Hill, Theodoros, Russell, \& Ward, 2009, Kully, 2000, Mashima et al., 2003, Theodoros, Hill, Russell, Ward, \& Wootton, 2008). Clinician satisfaction with telepractice has also been found to be high overall (ASHA, 2005, Kully, 2000, McCullough, 2001). In 2002, an ASHA survey of telepractice use indicated that $38 \%$ of speech-language 
pathologists who provided telepractice services did so in the public schools. However, reports of satisfaction surveys targeting school-based telepractice services have been scarce. The purpose of this pilot study was to determine the level of satisfaction of parents/guardians, teachers, and administrators with speech therapy by telepractice.

\section{TELESPEECH EQUIPMENT}

Because the quality of the videoconferencing equipment and infrastructure may affect the quality and perception of telepractice services, the specifics of the equipment are described here. The equipment used by the TeleSpeech Therapy project was as follows. Until October 30, 2008, the videoconferencing equipment used at the hub (UNCG Speech and Hearing Program) was a Polycom HDX 9000 codec with a 40" flat panel monitor and a high fidelity microphone delivering $22 \mathrm{kHz}$ audio. There was a high definition video camera with 180 degree panning and $12 x$ zoom capability. Sound was delivered through StereoSurround with $22 \mathrm{kHz}$ audio. At the remote site (the elementary school), there was a Polycom VSX 7000, a 32" flat panel monitor purchased by the school, and StereoSurround audio. The Polycom VSX 7000 does not have a high definition video camera. Both systems used H.323 network technology, which is currently an industry standard in high quality videoconferencing. The Polycom systems included a People+Content feature in which the speech-language pathologist could see, in synchrony, the remote site, the hub, and any documents/ images being displayed with the document camera and computer. These images can be configured in numerous ways to allow both sides to see what is needed.

On October 30, 2008, the videoconferencing equipment at both sites was replaced by Tandberg Edge 95 MXP models. The Edge 95 models include PrecisionHD high definition video cameras that can zoom in and out and move vertically and horizontally to pan the rooms (Crutchley, Dudley, \& Campbell, in press). Again, the Tandberg Edge 95 provides an $\mathrm{H} .323$ bandwidth up to 2Mbps. A 22" flat panel desktop monitor (Model LG 30DC LCD) was placed at the hub, and a 37" flat panel monitor (Model Mitsubishi MDT4025 LCD) was placed at the remote site. A DuoVideo feature of the Edge 95 allows for a picture-in-picture view. Thus, the hub could view the remote site as a large image with the document camera, a computer-based program, or the hub as an embedded small image (see Figure 1). Both sites could choose to display only one image rather than use the picture-inpicture feature (see Figure 2). In addition, the large image could display an item from a peripheral device with the remote or hub site as the small image (see Figure 3). The remote site could view the SLP in the large image with an image from a peripheral device as the small picture (see Figure 4). Regarding sound, the Tandberg Edge 95 delivers high quality $20 \mathrm{kHz}$ audio. The Edge $95 \mathrm{MXP}$ offers the highest level of embedded encryption of video and audio data, allowing for privacy and security.

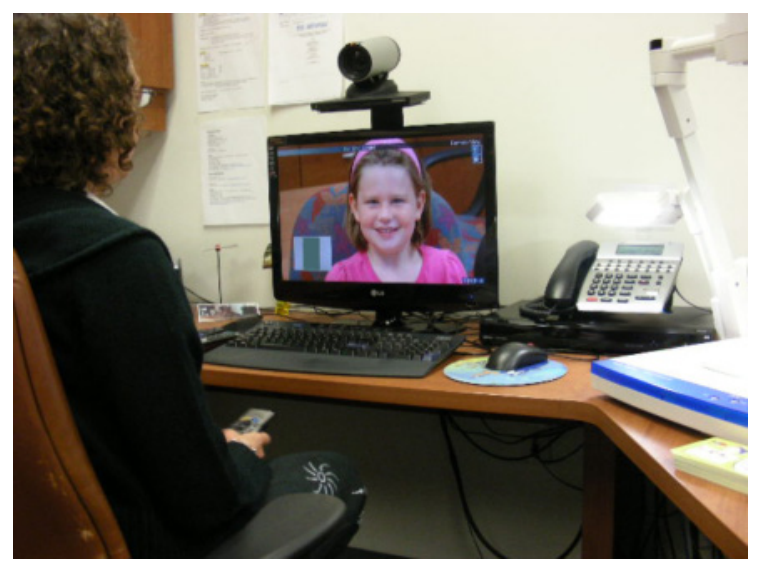

Figure 1. Image of client with document

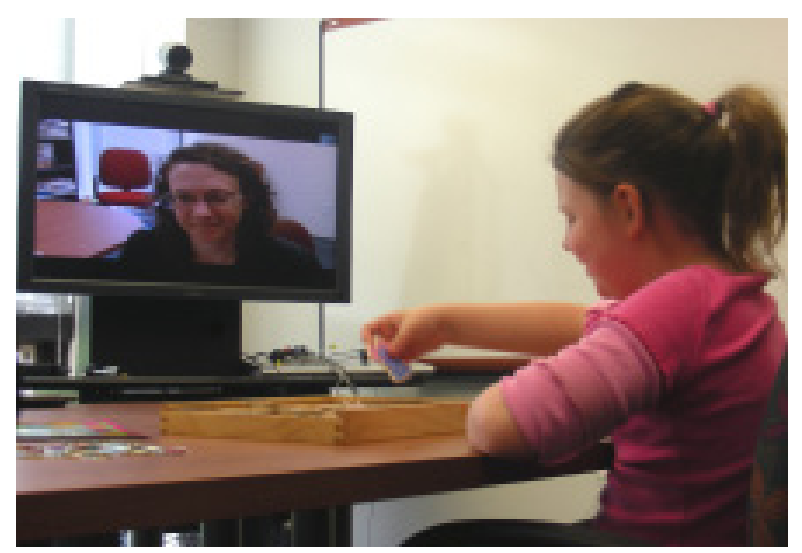

Figure 2. Full-screen image of SLP camera image as picture-in-picture

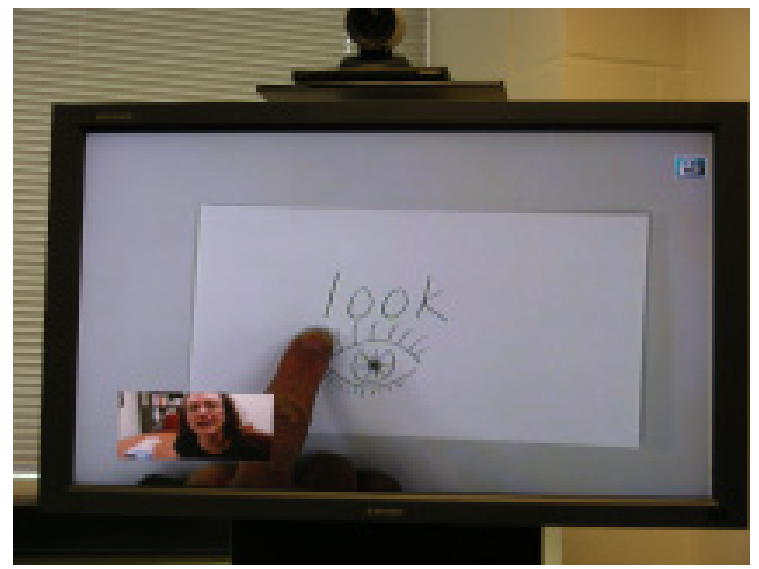

Figure 3. Large image from document camera with picture-in-picture image of SLP 


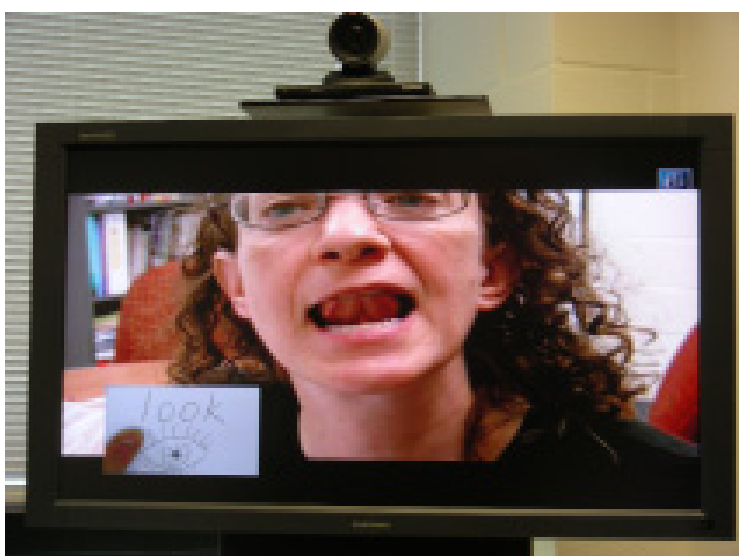

Figure 4. Large image of SLP with

document camera image as picture-in-picture

A document camera, the ELMO Visual Presenter, was utilized at the hub since the beginning of the project. In addition, the hub utilized the ability to transmit computerbased material (e.g., web-based applications, CD Rombased speech therapy materials) to the remote site through the videoconferencing equipment. On October 20, 2008, the remote site received an ELMO Visual Presenter document camera, providing that site the ability to display images to the hub.

Both sites had bidirectional, synchronous data rates of at least 384Kbps. The UNCG Speech and Hearing Program system utilizes a fiber connection with a bandwidth of $10 \mathrm{Mbps}$.

\section{TELEPRACTICE SATISFACTION SURVEY}

\section{PARTICIPANTS}

All teachers who taught students receiving TeleSpeech Therapy during the 2008-2009 school year, all administrators associated with the TeleSpeech Therapy project, and the parents and guardians of all students receiving TeleSpeech therapy during the 2008-2009 school year were invited to complete the satisfaction survey. Thus, 20 teachers, 6 administrators, and 33 parents/guardians were invited to complete the survey. Surveys were returned from 13 teachers (65\% return rate), 3 administrators (50\%), and 8 parents/guardians (24\%).

\section{PROCEDURES AND MATERIALS}

The satisfaction survey was developed by the telepractice SLP and program director with adaptations from a telehealth satisfaction survey of the Veterans Health Administration (2003). The survey statements only addressed the stakeholders' perception of telepractice rather than a comparison of telepractice with in-person services. Based on available information, many of the students had not received comparable in-person services. Some students had never had in-person services, or their frequency of services was less in person than it was by telepractice. In addition, in-person services sometimes involved larger group sizes than what was provided by telepractice. Thus, measuring telepractice in comparison to in-person speech therapy would not have provided a valid assessment.

Teachers, administrators and parents/guardians received identical surveys. Participants indicated on the survey whether they were a teacher, parent/guardian or administrator. The survey was based on a 5 point Likert scale ranging from 1 (strongly disagree) to 5 (strongly agree). It requested general feedback about the TeleSpeech Therapy program rather than information about specific students. The survey statements were developed to help the researchers determine what worked and what didn't work in the TeleSpeech program. An opportunity to write additional comments was provided on the survey. Overall, a goal of the satisfaction survey was to help the researchers improve the TeleSpeech Therapy program.

The surveys were to be sent out at the end of the 2008-2009 school year, which would give the participants the opportunity to experience a complete academic year of TeleSpeech Therapy. However, the contractual agreement with the public school system was terminated by that school district in March, 2009, due to reported financial constraints and technical challenges within their district. Thus, the study ended prematurely. Surveys could not be distributed until May 14, 2009 and were hand delivered to teachers and school administrators. On May 23,2009 , after approval for the survey and cover letter to parents/guardians was received from the school system's administrative office, the remaining surveys were mailed to parents/guardians and central office administrators.

\section{DATA COLLECTION \& ANALYSIS}

Surveys were returned in self-addressed stamped envelopes so that participants could remain anonymous. Surveys were collected until June 23, 2009. For each subgroup (i.e., parents, teachers/guardians, administrators), ratings were averaged for each question. They were also averaged across each subgroup per question.

\section{RESULTS}

A total of 24 surveys were returned, including 3 from administrators, 13 from teachers, and 8 from parents. As seen in Table 1, with average ratings above 4.0 except for the rating of item 1 by teachers, there was overall high satisfaction with the TeleSpeech Program. However, some individual ratings of 1 and 2 indicate that not all parents/guardians and teachers were satisfied with TeleSpeech. Administrators rated TeleSpeech with at least a 4 for each statement, suggesting that the administrators surveyed were highly satisfied with the TeleSpeech project. 
Table 1

Satisfaction Survey Ratings

Rating Scale: $1=$ Strongly Disagree $2=$ Disagree $3=$ Neutral $4=$ Agree $5=$ Strongly Agree

\begin{tabular}{|c|c|c|c|c|c|}
\hline \multirow[b]{2}{*}{ Statement } & & \multicolumn{4}{|c|}{ Ratings } \\
\hline & & Parents & Teachers & Administrators & Total \\
\hline \multirow{2}{*}{$\begin{array}{l}\text { 1. My expectations for } \\
\text { the TeleSpeech Therapy } \\
\text { program have been } \\
\text { met. }\end{array}$} & Mean & $4.13(n=8)$ & $3.92(\mathrm{n}=13)$ & $4.67(n=3)$ & $4.08(n=24)$ \\
\hline & Range & $3-5$ & $2-5$ & $4-5$ & $2-5$ \\
\hline $\begin{array}{l}\text { 2. Progress was made } \\
\text { toward speech-language }\end{array}$ & Mean & $4.13(n=8)$ & $4.23(\mathrm{n}=13)$ & $4.33(n=3)$ & $4.21(n=24)$ \\
\hline $\begin{array}{l}\text { IEP goals through the } \\
\text { TeleSpeech Therapy } \\
\text { program. }\end{array}$ & Range & $1-5$ & $2-5$ & $4-5$ & $1-5$ \\
\hline \multirow{2}{*}{$\begin{array}{l}\text { 3. I would recommend } \\
\text { TeleSpeech Therapy to } \\
\text { other school districts. }\end{array}$} & Mean & $4.38(n=8)$ & $4.33(\mathrm{n}=12)$ & $4.67(n=3)$ & $4.39(n=23)$ \\
\hline & Range & $3-5$ & $3-5$ & $4-5$ & $3-5$ \\
\hline $\begin{array}{l}\text { 4. The speech-language } \\
\text { pathologist providing } \\
\text { TeleSpeech Therapy was }\end{array}$ & Mean & $4.29(n=7)$ & $4.46(n=13)$ & $4.67(n=3)$ & $4.22(n=23)$ \\
\hline $\begin{array}{l}\text { easy to reach when } \\
\text { needed. }\end{array}$ & Range & $3-5$ & $2-5$ & $4-5$ & $2-5$ \\
\hline $\begin{array}{l}\text { 5. TeleSpeech Therapy } \\
\text { meets the speech- }\end{array}$ & Mean & $4.13(n=8)$ & $4.08(n=13)$ & $4.67(n=3)$ & $4.17(n=24)$ \\
\hline $\begin{array}{l}\text { language needs of the } \\
\text { students enrolled in the } \\
\text { program. }\end{array}$ & Range & $3-5$ & $2-5$ & $4-5$ & $2-5$ \\
\hline $\begin{array}{l}\text { 6. The speech-language } \\
\text { pathologist was }\end{array}$ & Mean & $4.29(\mathrm{n}=7)$ & $4.38(n=13)$ & $4.67(n=3)$ & $4.39(n=23)$ \\
\hline $\begin{array}{l}\text { responsive to my } \\
\text { concerns. }\end{array}$ & Range & $3-5$ & $2-5$ & $4-5$ & $2-5$ \\
\hline
\end{tabular}

(Veterans Health Administration, 2003, Westra et al., 1995)

In addition to rating the TeleSpeech Therapy pilot project, some of those surveyed provided additional comments (Table 2). Parents/guardians reported improvements in their children's communication skills as a result of TeleSpeech Therapy, while one parent suggested that in-person services are preferred. The majority of comments from the teachers reflected a positive view of the project. A couple of teachers commented on technological difficulties experienced during the project. The one administrator who provided additional comments reported on perceived benefits of telepractice. Overall, the majority of comments supported a positive perception of TeleSpeech Therapy.

Table 2.

Stakeholder Comments

Stakeholder Comments

Parents/ $\quad$ - "TeleSpeech therapy was better than nothing, but it does not replace or

Guardians exceed that one-on-one training."

- "I have noticed that since my son participated in the program his speech has become more clear. My son is also speaking more in sentences other than just in words."

- "My daughter is responding a lot better. Sometimes she talks a little too much. I like to thank you very much."

Teachers $\quad$ "Nothing is better than 1 on 1 - consistently. Too many technical problems and lack of therapy."

- "Despite technological difficulties, the therapists did a wonderful job."

- "...she [the student] made fast progress."

- "IEP goals met. Teacher of program wonderful..."

- "I very much enjoyed working with the speech-language pathologist...It was very well liked by the students..."

- "I felt this was a wonderful program. Students were picked up when they were supposed to be and I received feedback from the pathologist..."

Administrators - "Absolutely wonderful. TeleSpeech provided on target services to students Rural districts are able to serve students with limited personnel resources. Certainly TeleSpeech is $21^{\text {st }}$ Century quality and innovative use of limitations."

\section{DISCUSSION}

All but one item rated by one subgroup received an average rating above 4.0 , indicating that the majority of those surveyed at least agreed with the survey statements. The remaining item, based on the teachers' expectations of TeleSpeech Therapy, received an average rating of 3.92 , consistent with an overall positive perception of TeleSpeech Therapy. However, that statement does not distinguish between those who had high expectations for the program and those who had low expectations. Based on the mean satisfaction ratings from each subgroup, it appears that there was a high level of satisfaction with telepractice overall.

Some of the items may not have been applicable to all surveyed. For example, item 5 would have been difficult for parents/guardians to answer because they would not likely know how well the program suited children other than their own.

Regarding item 2, as with in-person speech therapy, it is difficult to clearly identify why some students make progress and others do not. Several factors influence success in speech therapy, such as a child's readiness to learn, the quantity and quality of practice outside speech sessions, and the speech-language pathologist's skill level. Thus, success or the lack thereof through TeleSpeech Therapy may or may not be related to the telepractice medium.

It is interesting to note the comments that contrasted TeleSpeech with "one-on-one" therapy. The TeleSpeech Therapy services were provided to either one child at a time or in groups of two. Thus, TeleSpeech Therapy often involved one-on-one services. It is not unusual for in-person school-based speech-language pathologists to serve students in groups of 3 and 4 . Thus, this TeleSpeech project often allowed for more individualized attention than is possible with some in-person programs. However, it is possible that those who used the phrase "one-on-one" were actually referring to "in-person" services.

Because the TeleSpeech Therapy pilot project ended prematurely, the results of the survey may be artificially deflated. In February, 2009, the morning after a new firewall was installed on the remote end, the videoconferencing connection was lost. Several attempts were made to restore the connection, but the school district ultimately chose to cease efforts due to budgetary constraints and their inability to allocate further IT support to the project. Thus, they cancelled the contract for telepractice services. The researchers were unable to inform the parents or teachers about the contract termination, as that information needed to be disseminated by the school district. Therefore, if parents/guardians or teachers saw declines in progress or a lack of progress toward the end of the school year, they may have attributed that to a flaw in telepractice services rather than to a lack of services due to contract 
termination. However, the fact that overall high ratings of satisfaction were received despite the premature termination in the TeleSpeech Therapy pilot project indicates a strong positive perception of telepractice as a service delivery method with the public school system involved in the project.

\section{FUTURE IMPLICATIONS}

Further research measuring the satisfaction of patients, students, and clients with telepractice would be valuable. In addition, measuring satisfaction with specific components of telepractice may be valuable. For example, satisfaction with conferences held by telepractice would be valuable to measure. Determining the SLP's and paraprofessional's satisfaction with telepractice would be useful. Additional specific information about what was desirable and what was unsatisfactory about telepractice would be helpful to learn. For example, if TeleSpeech Therapy did not meet a person's expectations, was that due to an occasional technical difficulty or scheduling challenges? And, was high satisfaction related to the quality of the sound and video?

Speech therapy by telepractice is relatively new and offers the potential to dramatically improve access to speech therapy services for those who are underserved. As more and more attention and resources are being directed toward telepractice, it is critical to know if satisfaction with these services is high enough to make it widely accepted by service providers, caregivers, and clients.

\section{CONCLUSIONS}

The results of this pilot study indicate overall high levels of satisfaction with a school-based TeleSpeech Therapy pilot project by parents, teachers, and administrators. However, the results of this study may be deflated due to the pilot project being terminated prematurely by the school district due to budgetary constraints. Despite the project ending early, satisfaction levels were high overall. This study suggests that telepractice provided an acceptable service delivery model of speech therapy for the school system involved in the project.

\section{ACKNOWLEDGEMENTS}

This research was supported by federal earmark dollars from the United Stated Department of Education. The UNCG Institutional Review Board determined that this study does not constitute human research. The authors wish to thank David Brennan of the Center for Applied Biomechanics \& Rehabilitation Research, National Rehabilitation Hospital, for his assistance with the creation of our satisfaction survey. Lastly, the child in the photographs is not an actual client, and written permission for the UNCG Speech and Hearing Program to use those pictures was obtained from her parent. 


\section{REFERENCES}

American Speech-Language-Hearing Association. (2002). Survey report on telepractice use among audiologists and speech-language pathologists. Available from http://www.asha.org/uploadedFiles/practice/ telepractice/SurveyofTelepractice.pdf

American Speech-Language-Hearing Association. (2005). Speech-language pathologists providing clinical services via telepractice: position statement [position statement]. Available from http://www.asha.org/docs/ html/PS2005-00116.html

Brennan, D., Georgeadis, A., Baron, C., \& Barker, L. (2004). The effect of videoconference-based telerehabilitation on story retelling performance by brain-injured subjects and its implications for remote speech-language therapy. Telemedicine Journal \& e-Health, 10, 147-154.

Council for Allied Health in North Carolina (2001). Communicating the trends: The speech-language pathology workforce in North Carolina. Chapel Hill, NC.

Authors (in press). Articulation assessment through videoconferencing: A pilot study. Communications in Global Information Technology.

Forducey, P. (2006). Speech telepractice program expands options for rural Oklahoma schools. ASHA Leader, 11, 12-13.

Hill, A., Theodoros, D., Russell, T., Cahill, L., Ward, E., \& Clark, K. (2006). An internet-based telerehabilitation system for the assessment of motor speech disorders: A pilot study. American Journal of Speech-Language Pathology, 15, 45-56.

Hill, A., Theodoros, D., Russell, T., \& Ward, E. (2009). The redesign and re-evaluation of an internet-based telerehabilitation system for the assessment of dysarthria in adults. Journal of Telemedicine and e-Health, 15 (9), 840-850.

Kully, D. (2000). Telehealth in speech pathology: Applications to the treatment of stuttering. Journal of Telemedicine and Telecare, 6 (Suppl 2): S2:39-S2:41.

Mashima, M., Birkmire-Peters, D., Syms, M., Holtel, M., Burgess, L., \& Peters, L. (2003). Telehealth: Voice therapy using telecommunications technology. American Journal of Speech-Language Pathology, 12, 432-439.

Mashima, M. \& Doarn, C. (2008). Overview of telehealth activities in speech-language pathology. Telemedicine and e-Health, 14 (10), 1101-1117.

McCullough, A. (2001). Viability and effectiveness of teletherapy for preschool children with special needs. International Journal of Language and Communication Disorders, 36 (suppl.), 321-326.

Theodoros, D., Hill, A., Russell, T., Ward, E., \& Wootton, R. (2008). Assessing acquired language disorders in adults via the internet. Journal of Telemedicine and e-Health, 14 (6), 552-559.
Veterans Health Administration (VHA). Office of Care Coordination Services. 2003. Home telehealth patient satisfaction survey.

Westra, B., Cullen, L., Brody, D., Jump, P., Geanon, L., \& Milad, E. (1995). Development of the home care client satisfaction instrument. Public Health Nursing. 12 (6). 393-399. 


\section{ALTERNATIVE DESCRIPTIONS FOR PHOTOS}

Figure 1. The female SLP is seated, looking at a head and shoulders view of the client, an elementary schoolaged girl, in full-screen on her 22" flat panel desktop monitor. On the bottom left hand corner of the monitor, the SLP sees the image of a flash card in a 3" by 5" picture-in-picture image. She presents that image using the document camera which is to her right on her desk. Using the remote control, the picture-in-picture image can be placed in any corner of the monitor. The video camera capturing the SLP for the client is housed above the monitor. The microphone rests on the desk to the left of the SLP, although it can be moved around as needed.

Figure 2. The client is sitting at a table, playing with a manipulative toy. The client sees the SLP in full-screen on a 37" flat panel monitor on a cart in front of her. The child sees a head and shoulders image of the SLP and some of the SLP's office in the background. The video camera that is capturing the child's image for the SLP rests on a stand above the monitor. The microphone which is out of view in the picture rests on the table beside the child.

Figure 3. There is a close-up picture of the 37" television that the child sees. In the full-screen image is a flash card that the SLP is presenting using the document camera. The flash card says "look" and has a picture of an eye. The SLP's finger pointing to the letter "I" is visible. On the bottom left hand corner of the screen is the 3 " by 5" picture-in-picture image of the SLP demonstrating for the child what she should do with her tongue to produce the "I" sound. On the top right hand corner of the television is an icon of two closed locks indicating that the signal is encrypted.

Figure 4. A close-up picture of the 37" television shows the image from figure 3 reversed. The SLP demonstrating how to produce the "I" sound is in the large image, zoomed in to see her mouth about 9 inches wide. The picture in picture image on the bottom left hand corner is of the flash card from figure 3 with the SLP pointing to the letter "I." The image of the small encryption icon is on the top right corner. 